Scientific Journal of Hamadan Nursing \& Midwifery Faculty - ISSN 2008-2819

\title{
Survey of Nurses' Job Satisfaction in Educational and Therapeutic Cen- ters of Hamadan University of Medical Sciences
}

\author{
Amir Sadeghi', Asgar Goharloo Arkawaz ${ }^{2}$, Fatemeh Cheraghi ${ }^{3 *}$, Abbas Moghimbeigi ${ }^{4}$ \\ 1. Assistant Professor, Research Center for Child \& Maternity Care, Hamadan University of Medical Sciences \& Health \\ Services, Hamadan, Iran \\ 2. MSc in Nursing Management, Student Research Committee, Hamadan University of Medical Sciences \& Health Services, \\ Hamadan, Iran \\ 3. Associate Professor, Chronic Diseases (Home Care) Research Center, Hamadan University of Medical Sciences, Hama- \\ dan, Iran \\ 4. Associate Professor, Modeling of Noncommunicable Diseases Research Center, Hamadan University of Medical Sciences \\ \& Health Services, Hamadan, Iran
}

\begin{tabular}{lr}
\hline \multicolumn{2}{c}{ Article Info } \\
\hline & \\
Received: & $2017 / 01 / 31$ \\
Accepted: & $2017 / 09 / 02$ \\
Published Online & $2018 / 03 / 16$
\end{tabular}

DOI: $10.30699 /$ sjhnmf.26.1.40

Original Article

Use your device to scan and
read the article online

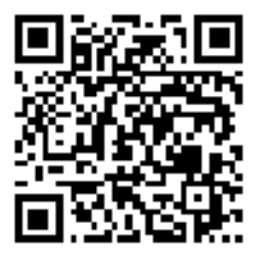

Abstract

Introduction: Job satisfaction is one of the effective factors on the quality of the nurses' performance. Therefore, studying these main organizational variables has been considered by many researchers. This study analyzes nurses' job satisfaction in Hamadan educational hospitals.

Methods: This is an analytic-descriptive study that was performed on 304 nurses chosen via stratified random sampling of relative type in Hamadan University of medical sciences' hospitals. Data collection tools included Spector's job satisfaction questionnaires, descriptive statistics (mean and standard deviation), inferential statistics, independent sample t-test, ANOVA, and Tukey post-hoc.

Results: The results showed that the majority of participants $74.3 \%$ ) had moderate job satisfaction level, $1.3 \%$ percent had high job satisfaction level and $24.4 \%$ percent had low job satisfaction level..Participants in areas of supervision (\%51), co-workers $(\% 51)$ and nature of work (\%53) had high level of job satisfaction, in terms of promotion $(\% 46 / 7)$ and communication (\% 48/4) they had moderate level of job satisfaction, and regarding payment (\%69/1), contingent rewards $(\% 79 / 6)$, operating conditions $(\% 91 / 4)$, and fringe benefits $(\% 79 / 6)$ they had low level of job satisfaction. There was a significant statistical difference in nurses' job satisfaction based on their gender $(\mathrm{t}=2.8, P=0.005)$ and job experience $(\mathrm{F}=4.95, P=0.005)$. There was not a significant statistical difference in nurses' job satisfaction based on their age.

Conclusions: The results showed that nurses in the areas of payment, contingent rewards, fringe benefits and operating condition were least satisfied. Therefore, it is expected that the custodians pay more attention to economic components of nursing jobs and reduce unnecessary bureaucracy.

Keywords: Job satisfaction, Nurses, Demographic characteristics, Hamadan

Copyright $($ C 2018, Sci J Hamadan Nurs Midwifery Fac. This is an open-access article distributed under the terms of the Creative Commons Attribution-noncommercial 4.0 International License which permits copy and redistribute the material just in noncommercial usages, provided the original work is properly cited.

How to Cite This Article:

Sadeghi A, Goharloo Arkawaz A, Cheraghi F, Moghimbeigi A. Survey of Nurses' Job Satisfaction in Educational and Therapeutic Centers of Hamadan University of Medical Sciences. Sci J Hamadan Nurs Midwifery Fac. 2018; 26 (1): 40-48 
مجله علمى دانشكده هرستارى و مامايى همدان - شايا الكترونيك: 19

مقاله يثوهشى

\section{بررسى رضايت شغلى :رستاران شاغل در مراكز آموزشى درمانى دانشعاه علوم يزشكى همدان}

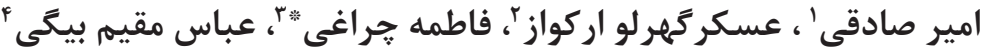

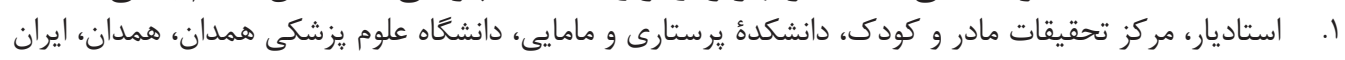

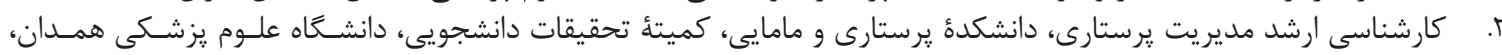

همدان، ايران

r. دانشيار، مركز تحقيقات مراقبت بيمارىهاى مزمن در منزل، دانشكدهُ يرستارى و مامايى، دانشعاه علوم بزشكى همدان، همدان،

f. دانشيار، مركز تحقيقات مدلسازى بيمارىهاى غيرواگير، زروه آمار زيستى، دانشكده بهداشت، دانشخاه علوم يزشكى همدان،

همدان، ايران

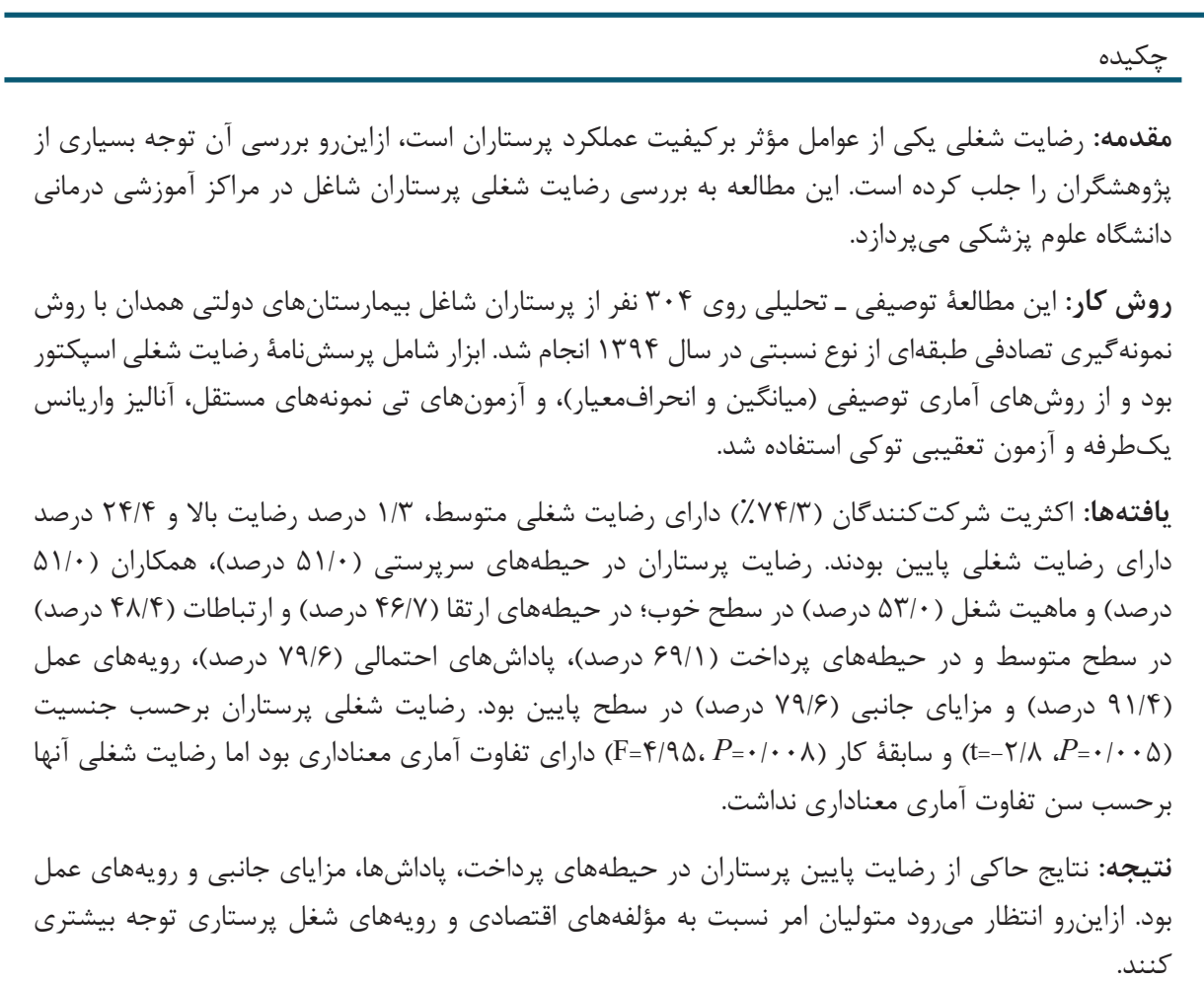

| اطلاعات مقاله

\begin{tabular}{|c|}
\hline مقاله \\
\hline $14 q \Delta / 11 / 14$ \\
\hline 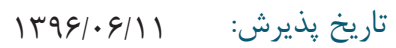 \\
\hline $\mid r q \varepsilon / 1 T / T \Delta$ \\
\hline نويسندهُمسئول: \\
\hline فاطمه تجراغى \\
\hline دانشيار، مركز تحقيقات مراقبت \\
\hline بيمارىهاى مزمن در منزل، \\
\hline دانشكدة يرستارى و مامايى، \\
\hline دانشعاه علوم يزشكى همدان، \\
\hline همدان، ايران \\
\hline تلفن: \\
\hline 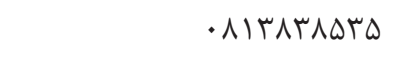 \\
\hline يست الكترونيك: \\
\hline f_cheraghi@yahoo.com \\
\hline
\end{tabular}

وازههاى كليدى: رضايت شغلى، يرستاران، مشخصات دمو گرافيك، همدان

سازمان بهتر خواهد بود. بى توجهى مديران به رضايت شغلى ماهي

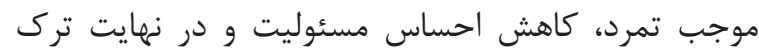

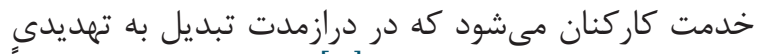

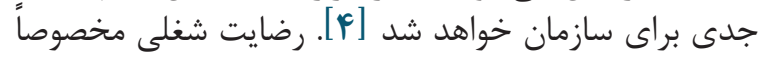

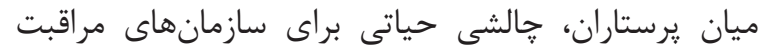

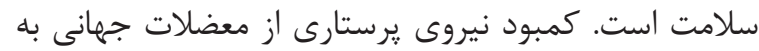

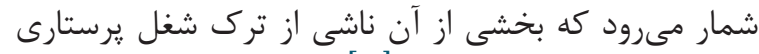

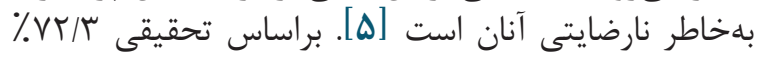

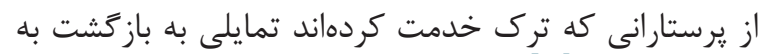

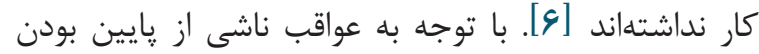

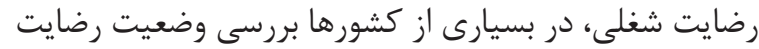

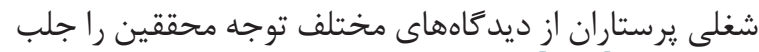

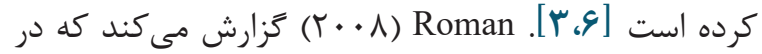

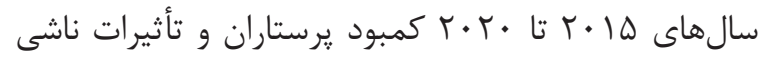
دوره צr شماره | - فروردين و ارديبهشت Vوس|

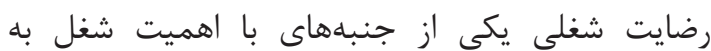

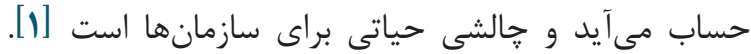

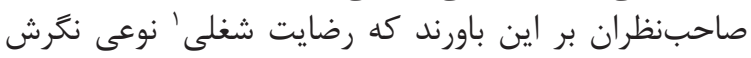

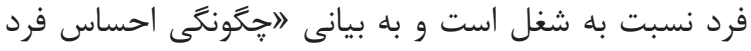

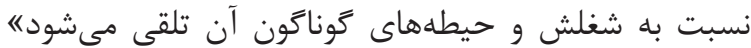

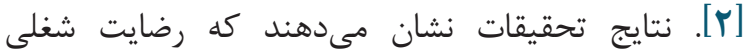

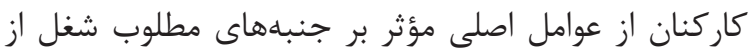

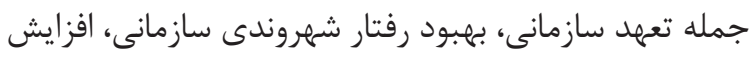

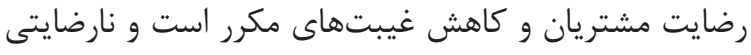

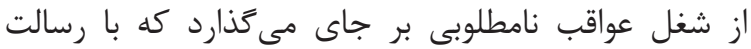

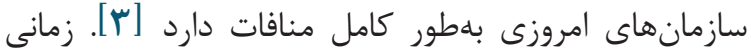

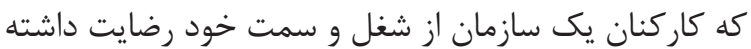

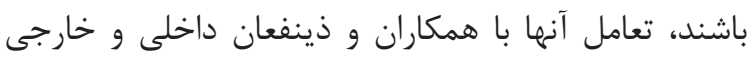

Job Satisfaction $\quad$ ।

مجله علمى دانشكده يرستارى و مامايى همدان 


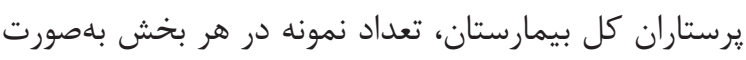

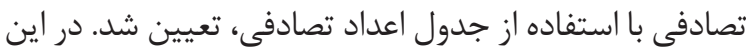

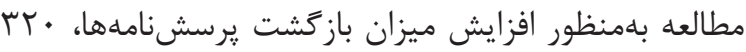

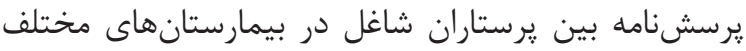

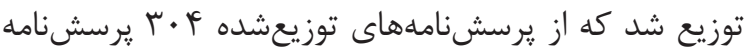

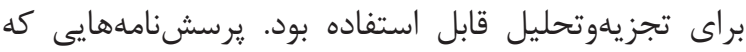

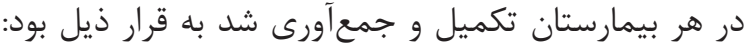

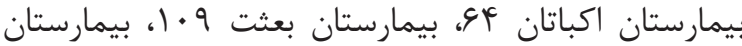

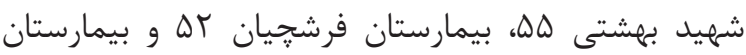

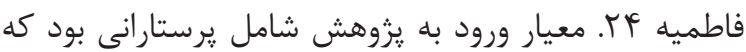

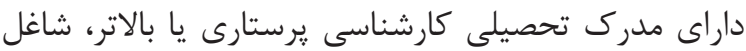

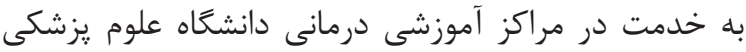

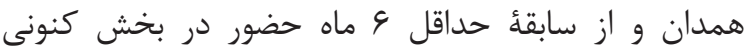

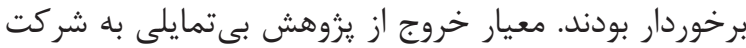

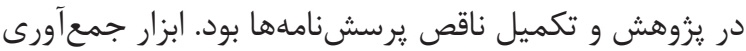

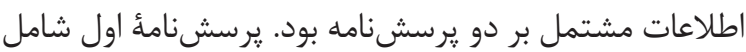

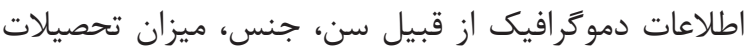

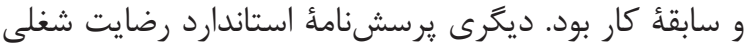

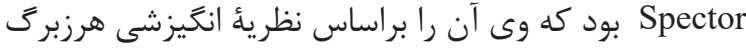

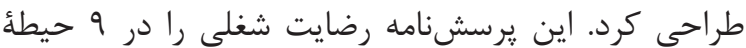

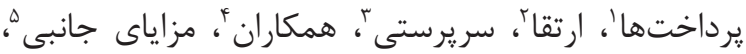

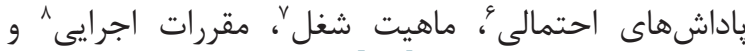

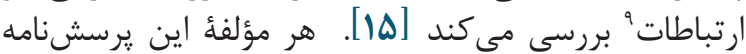

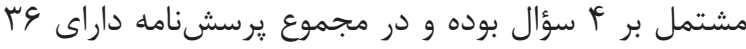

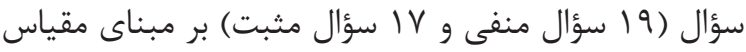

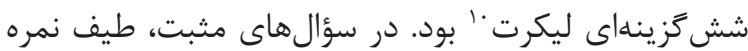

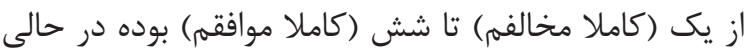

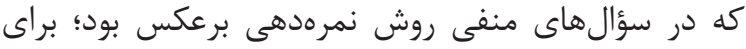

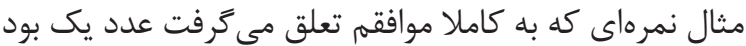

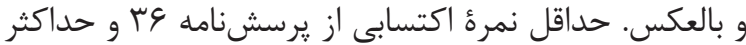

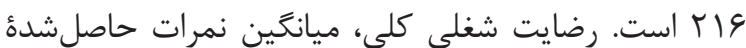

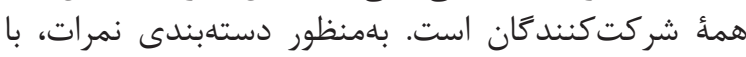

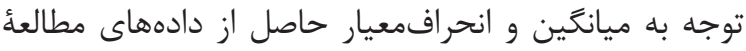

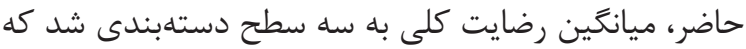

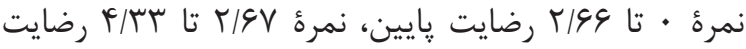

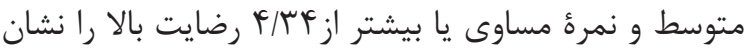

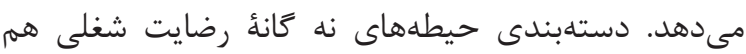

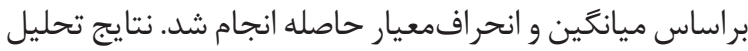

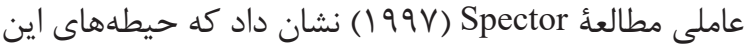

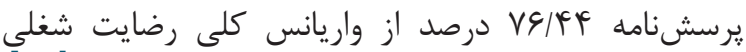

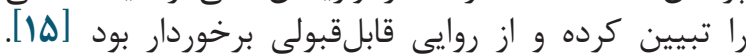
Akbaritabar

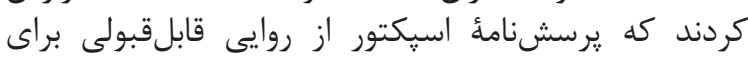

1. Pay

2. Promotion

3. Supervision

4. Coworker

5. Fringe benefits

6. Contingent reward

7. Nature of work

8. Operation condition

9. Communication

10. Likert
از آن به بيشترين حد خود خواهد رسيد و تهديدى جدى در بهان بهان

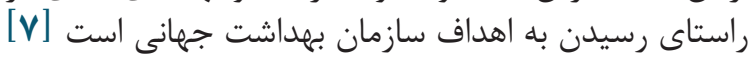

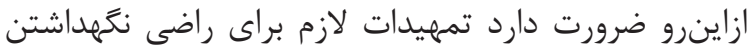

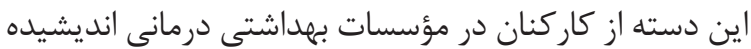

$$
\text { شود. }
$$

عوامل مختلفى بر رضايت شغلى برستار مؤثرند. براساس

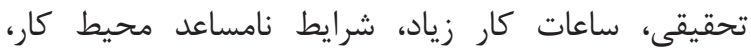

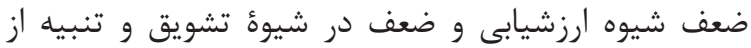

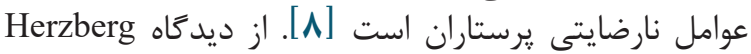

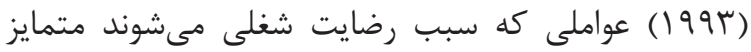

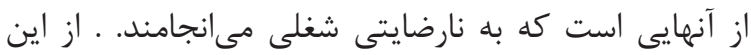

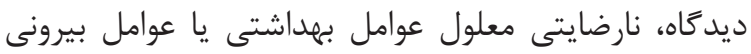

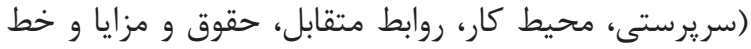

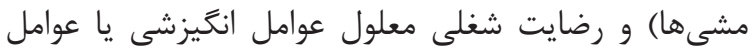

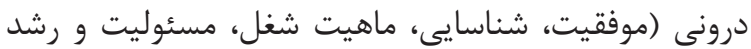

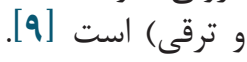

نارضايتى شغلى كاركنان در سازمانهاى متولى سلامت،

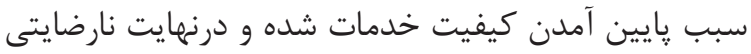

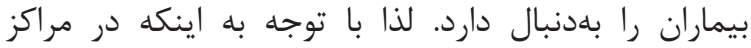

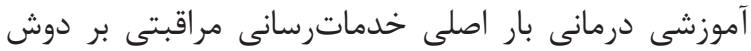

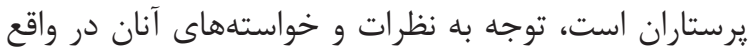

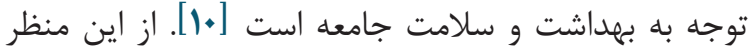

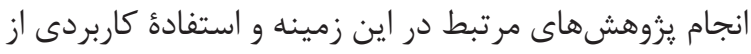

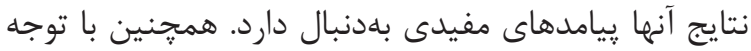

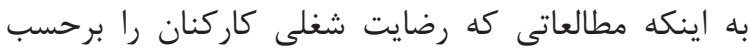

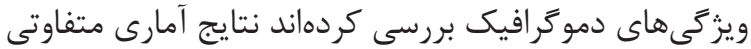

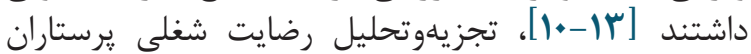

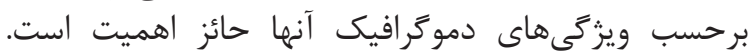

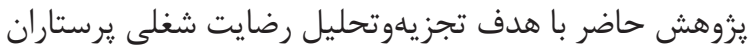

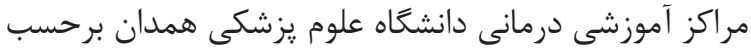

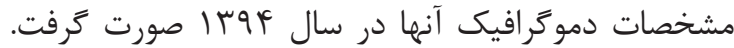

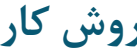

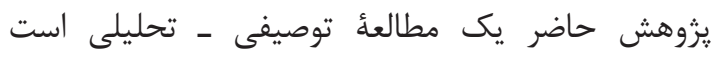

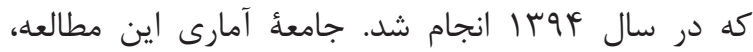

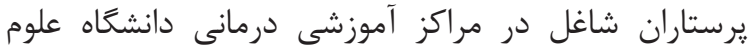

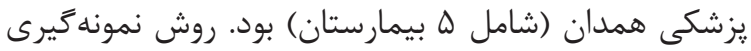

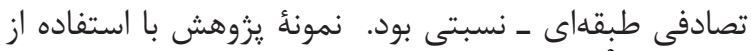
فرمول n تعيين شد كه در اين فرمول با

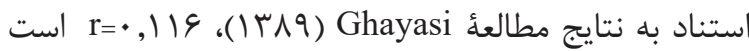

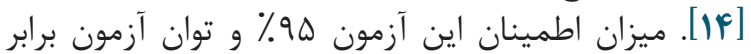

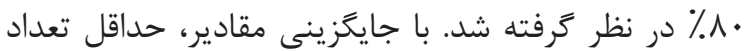

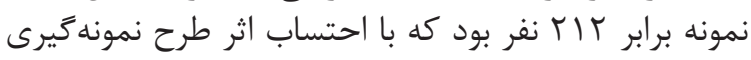

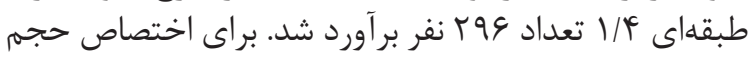

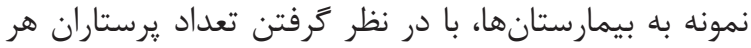

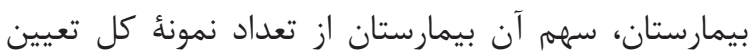

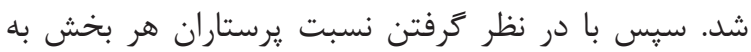


محققين و ديخر كاركنان امكان تورش را افزايش مى إداد، به

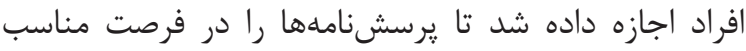

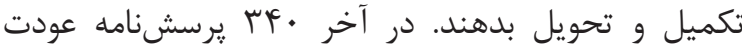

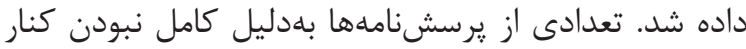

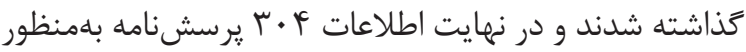

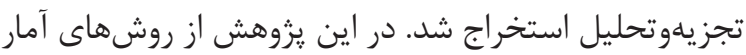

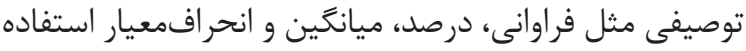

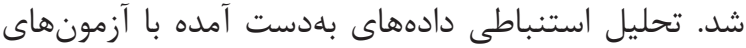

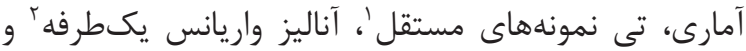

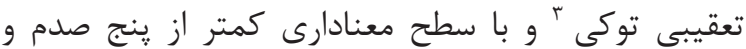

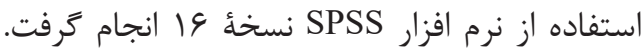

\section{يافتلها}

نتايج نشان داد كه VD/V درصد از شركت كنند

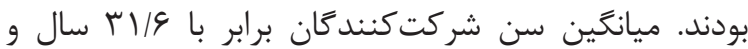

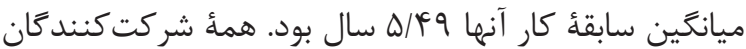
داراى مدرك تحصيلى كارشناسى يرستارى بودند. اكثريت شر كت كنند

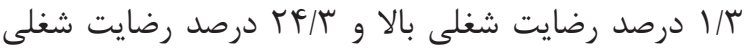

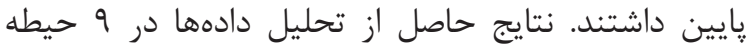

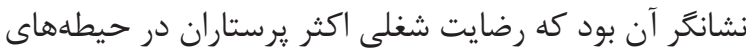

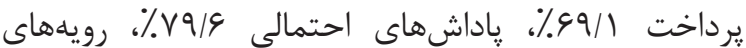

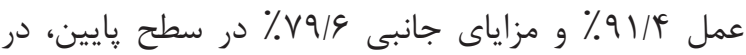

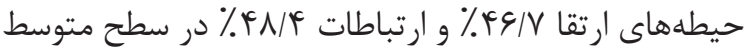

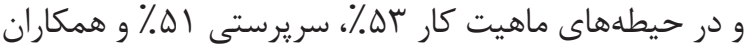
اه \% در سطح بالا بود (جدول ماهيط ().
سنجش رضايت شغلى كاركنان در جامعأه ايران برخوردار

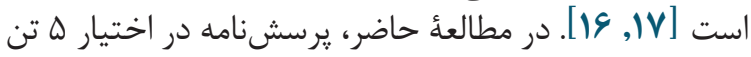

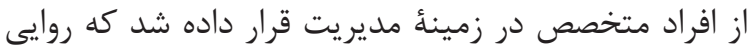

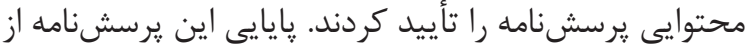

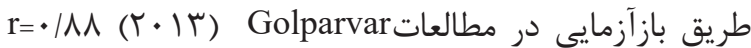
g $r=\cdot / 91$ (199V) Spector، $r=\cdot / \Lambda \Lambda$ ( $r \cdots r)$ Zaki

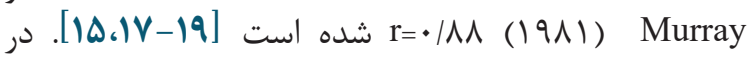

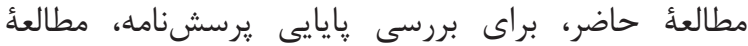

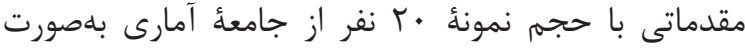

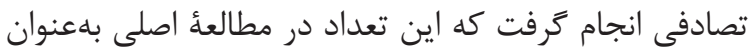

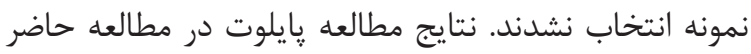

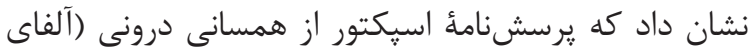

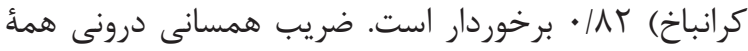

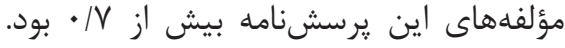

يس از دريافت مجوزهاى لازم همجون معرفىنامه از

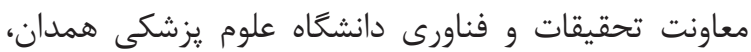

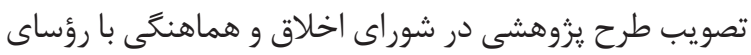

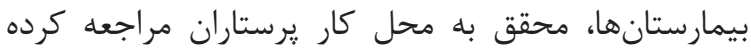

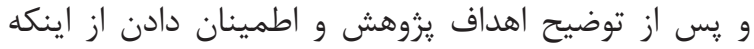

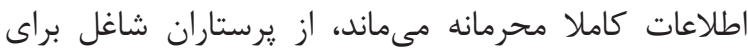

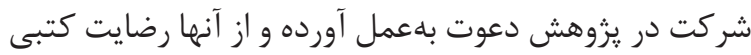

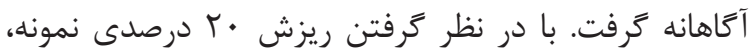

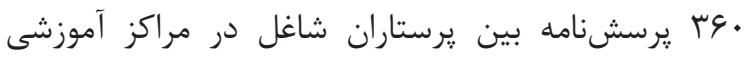

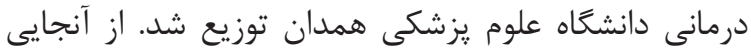
كه حضور سريرستار براى يرسنل صبح كار و و يأن حتى حضور

جدول شماره ا. توزيع فراوانى مطلق و نسبى رضايت شغلى يرستاران

\begin{tabular}{|c|c|c|c|c|c|}
\hline ارزيابى & ميانكين土 انحرافمعيار & درصد & تعداد & سطوح & متغير \\
\hline متوسط & $r / r_{ \pm} \cdot q$ & $\begin{array}{l}1 / F \\
V F / r \\
r \xi / r\end{array}$ & $\begin{array}{l}r \\
r{ }^{\prime} \\
V F\end{array}$ & متائلا & رضايت شغلى كلى \\
\hline بايين & $T / Y T_{ \pm} \cdot / \Lambda F$ & $\begin{array}{l}1 / r \\
r q / 9 \\
99 / 1\end{array}$ & $\begin{array}{c}4 \\
9 . \\
\text { ri. }\end{array}$ & متالا & يرداخت \\
\hline متوسط & $r / A V_{ \pm} / / T$ & $\begin{array}{l}1 / q \\
F \in / V \\
F F / \mathcal{F}\end{array}$ & $\begin{array}{l}\text { rV } \\
\text { IFr } \\
\text { IrD }\end{array}$ & متوسط & متوسط ارتقا \\
\hline بالا & $f / r \Delta_{ \pm} 1 / \cdot q$ & $\begin{array}{l}\Delta 1 / \cdot . \\
F 1 / \Lambda \\
V / r\end{array}$ & $\begin{array}{l}I \Delta D \\
I T V \\
r T\end{array}$ & متايتن & سريرستى \\
\hline קإيين & $T / / \Delta_{ \pm} \cdot / \wedge \Delta$ & $\begin{array}{l}r / \mid \\
\mid N / \mathcal{A} \\
V q / \Delta\end{array}$ & $\begin{array}{c}q \\
\Delta G \\
\text { IFT }\end{array}$ & متايّن & ياداشهاى احتمالى \\
\hline متوسط & $F / T \wedge \pm \cdot / 9 \Delta$ & $\begin{array}{c}\Delta 1 / . \cdot \\
\psi \Delta / / \\
r / q\end{array}$ & $\begin{array}{l}100 \\
1 T V \\
1 T\end{array}$ & متايين & همكاران \\
\hline متوسط & $F / T V_{ \pm} \mid / r$ & $\begin{array}{l}\Delta r / . . \\
r q / \Delta \\
1 \cdot / \Delta\end{array}$ & $\begin{array}{l}191 \\
111 \\
4 r\end{array}$ & متوسط & ماهيت شغل \\
\hline
\end{tabular}

1. Independent $T$ test

2. ANOVA

3. Tukey post- hoc 


\begin{tabular}{|c|c|c|c|c|c|}
\hline ارزيابى & ميانكَين土 انحرافمعيار & درصد & تعداد & سطوح & متغير \\
\hline يايين & $1 / \Delta F_{ \pm} \cdot / q V$ & $\begin{array}{l}\cdot / V \\
V / q \\
91 / 4\end{array}$ & $\begin{array}{l}r \\
r F \\
r Y A\end{array}$ & متائ & رويههاى عمل \\
\hline يايين & $r / \cdot r_{ \pm} \cdot / \Lambda \Lambda$ & $\begin{array}{l}1 / 4 \\
19 / 1 \\
19 / 9\end{array}$ & $\begin{array}{c}F \\
\Delta \Lambda \\
T F Y\end{array}$ & متائن & مزاياى جانبى \\
\hline متوسط & $r / r \mid \pm 1 / r$ & $\begin{array}{l}I V / V \\
Y N / F \\
r r / q\end{array}$ & $\begin{array}{l}\Delta F \\
1 F V \\
1 . r\end{array}$ & متائل & ارتباطات \\
\hline
\end{tabular}

每

جدول شماره r. مقايسهُ رضايت شغلى يرستاران براساس جنسيت آنها (آزمونt نمونههاى مستقل)

\begin{tabular}{cccccc} 
متغير & & & \\
\hline
\end{tabular}

يرستاران برحسب سن آنان تفاوت آمارى معنادارى نداشت

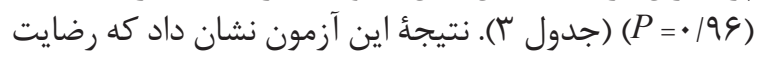

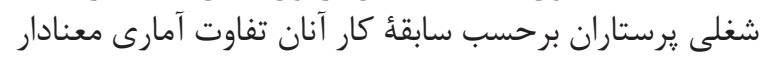

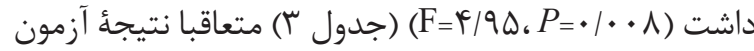

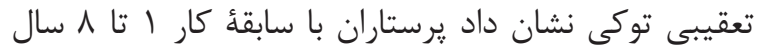

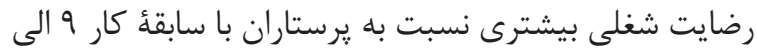

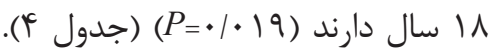

براساس نتايج، يرستاران زن از رضايت شغلى بيشترى

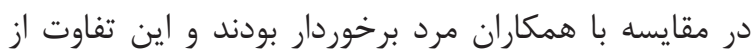

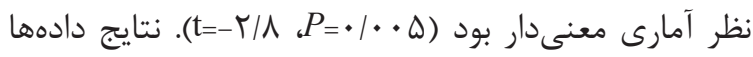

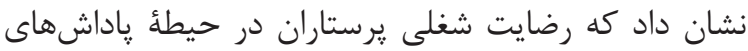

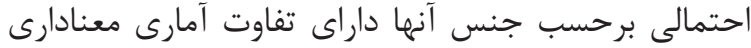

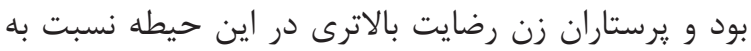

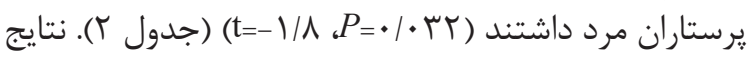

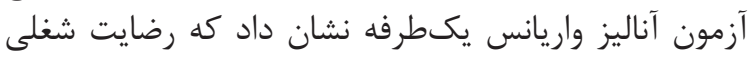

جدول شماره ب. مقايسُٔ رضايت شغلى يرستاران براساس كروه سنى و سابقءُ كار آنها (آزمون A N O V A)

\begin{tabular}{|c|c|c|c|c|c|c|}
\hline سطح معنادارى & درجهُ آزادى & آماره F & $\geq F 1$ & 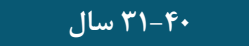 & ·r. & سن \\
\hline & & & ميانگين (انحر افمعيار) & ميانكين (انحرافمعيار ) & ميانغين (انحرافمعيار) & \\
\hline .1 .99 & $\begin{array}{c}d f)=r \\
d f r=r \cdot 1\end{array}$ & t/RG & $(\cdot / \uparrow q) r / q$. & $(\cdot / 94) \Gamma / 99$ & $(\cdot \mid G T) T / I T$ & رضايت شغلى \\
\hline سطح معنادارى & درجه آزادى & F آماره F & $\geq 19$ & 1A-9 سال & 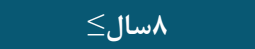 & سابقه كار \\
\hline & & & (انحرافمعيار) ميانگين & (انحرافمعيار ) ميانگين & (انحرافمعيار ) ميانگين & \\
\hline$\cdot 1 \cdot 1$ & $\begin{array}{c}d f)=r \\
d f r=r \cdot l\end{array}$ & $r / 90$ & $T / V(\cdot \mid \Delta \Lambda)$ & $r / 9(\cdot / 9 \cdot)$ & $r / 1(\cdot / 9 T)$ & رضايت شغلى \\
\hline
\end{tabular}

جدول شماره F. مقايسهُ ميانغين رضايت شغلى يرستاران برحسب سابقهُ كار آنها (آزمون تعقيبى توكى)

\begin{tabular}{|c|c|c|c|c|}
\hline سطح معنادارى & اختلاف ميانكين & سابقة كار & & متغير \\
\hline .1 .19 & $\cdot / \pi r q$ & $9-11$ & \multirow{2}{*}{ ^ سال> } & \multirow{6}{*}{ رضايت شغلى } \\
\hline$\cdot / l \Delta V$ &.$/ 44 q$ & $\geq 19$ & & \\
\hline .1 .19 & . & 1 سال> & \multirow[t]{2}{*}{ 11ا_9 سال } & \\
\hline - IAFA & .1111 & $\geq 19$ & & \\
\hline$\cdot / 1 \Delta V$ &.$/ r 4 q$ & ل 1 سال> & \multirow[t]{2}{*}{ 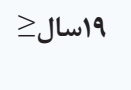 } & \\
\hline - $/ A F \Delta$ & .1111 & $9-11$ & & \\
\hline
\end{tabular}


يرستارانى كه احساس كنند فرصتى براى يُيشرفت دارند

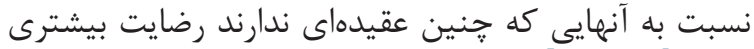

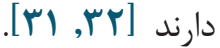

نتايج مطالعه نشان داد كه رضايت يرستاران در حيطأ

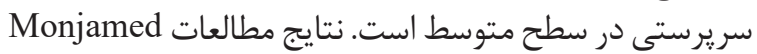

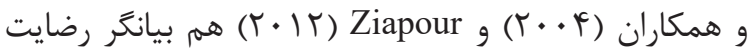

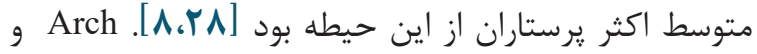
Greatz

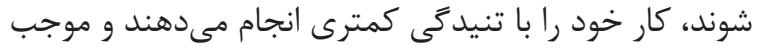

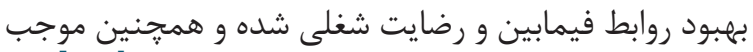

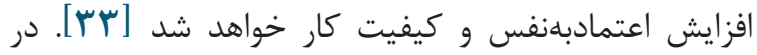

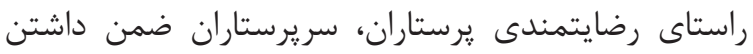

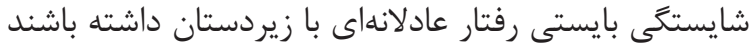
و به احساسات آنها توجه كنند.

نتايج نشان داد كه رضايت اكثر يرستاران در حيطة مزائه

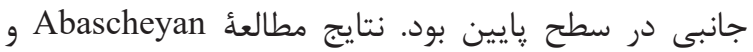

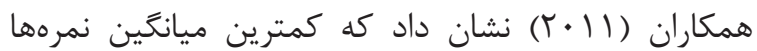

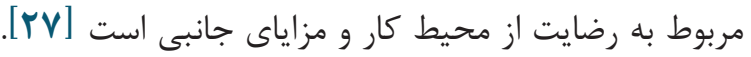

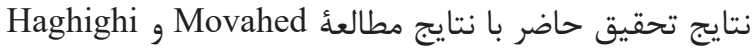

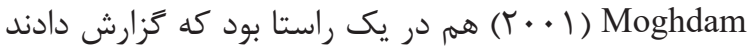

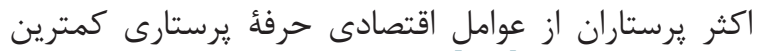

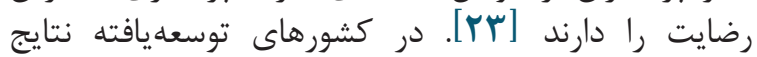

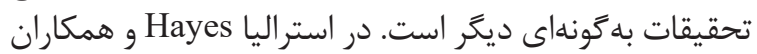

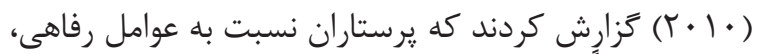

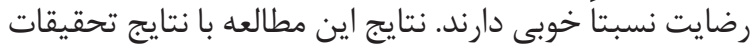

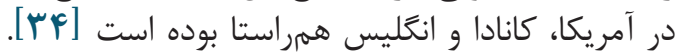

نتايج دادهها نشان داد كه رضايت اكثر يرستاران در حيطؤ

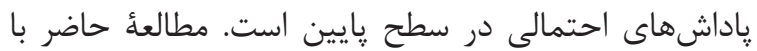

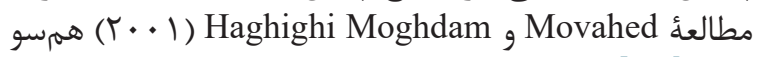

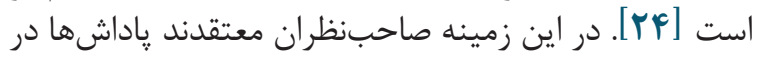

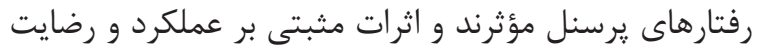

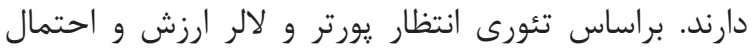

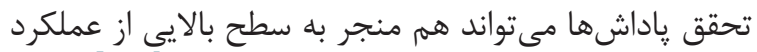

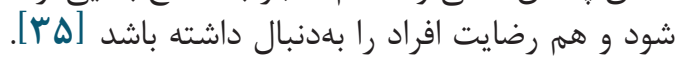

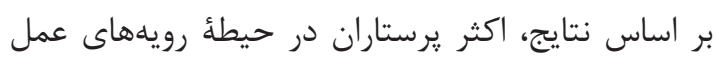

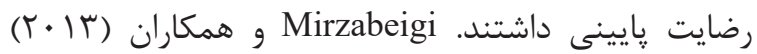

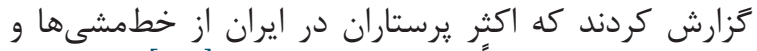

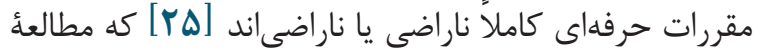

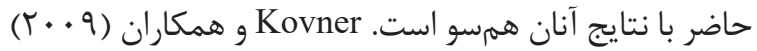

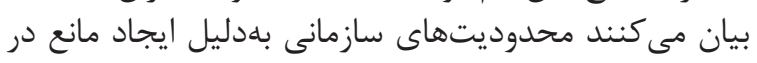

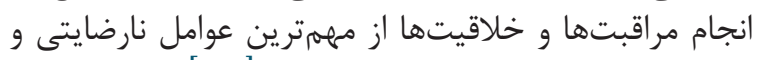

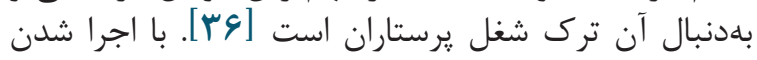

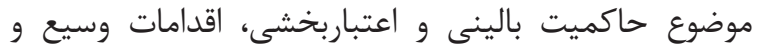

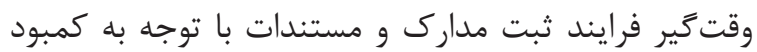

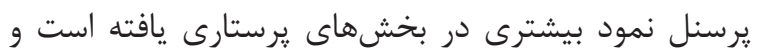

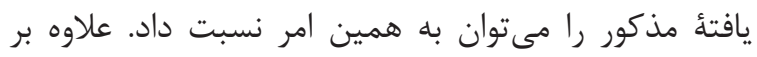

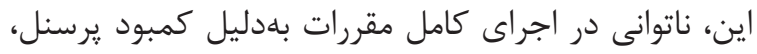
كماطلاعى نسبت به قوانين و مقررات و خطمشى مقرات بها و وابل كمبهد برسي،
بحث

يافتههاى تحقيق حاضر نشان داد كه ميانكين

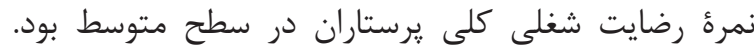

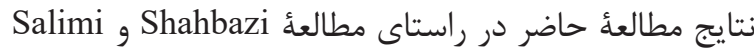

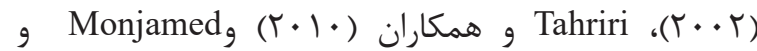

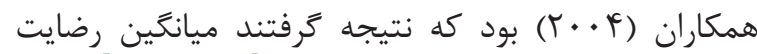

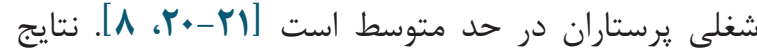

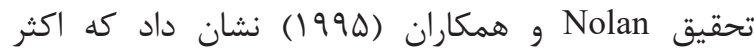

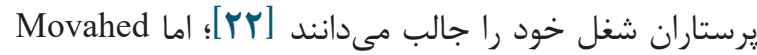

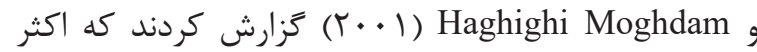

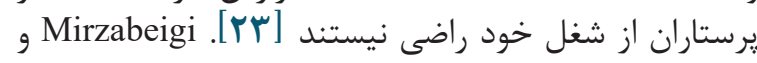

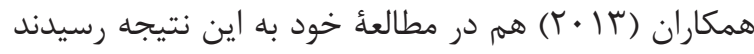

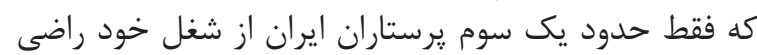

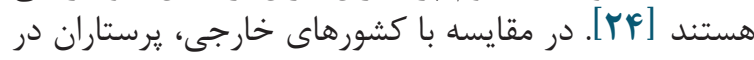

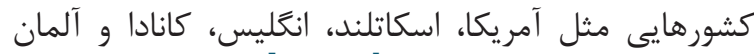

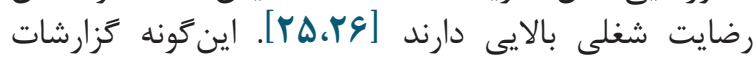

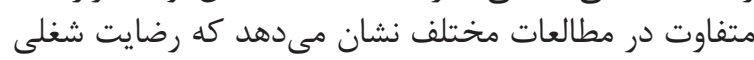

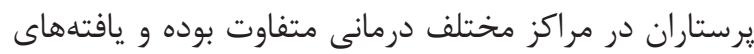

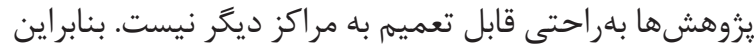

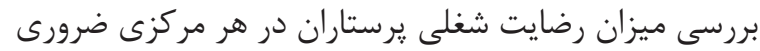

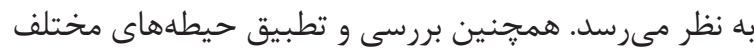

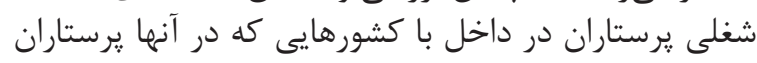

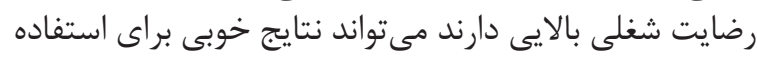

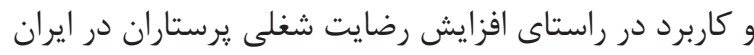

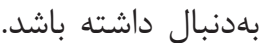

نتايج دادهها نشان داد رضايت شغلى اكثر شركت كنبند بركان

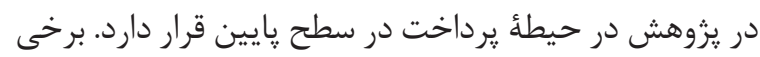

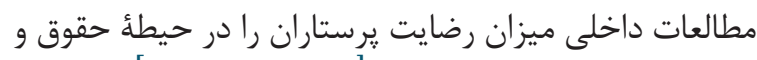

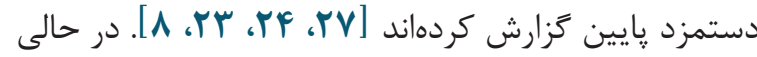

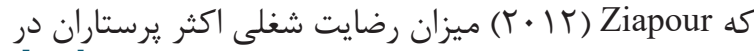

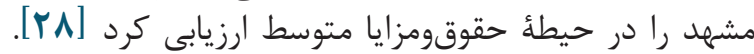

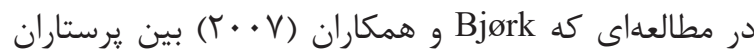

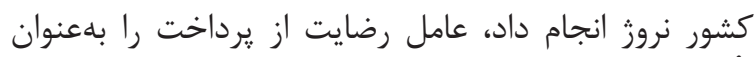

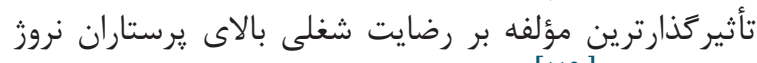

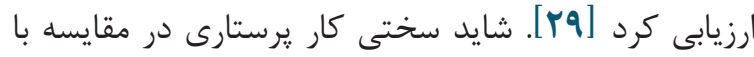

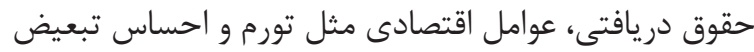

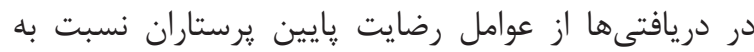
حيطهُ شغلىشان باشد.

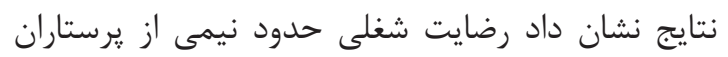

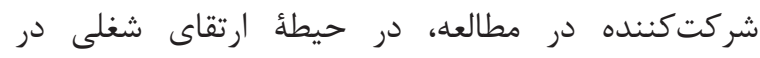

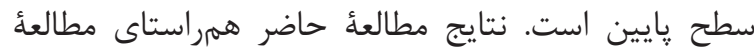
Mirzabeigi

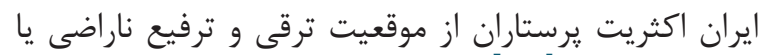

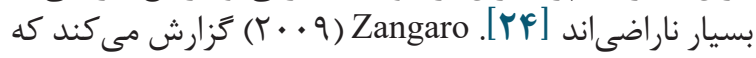

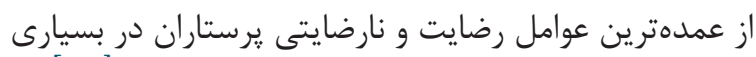

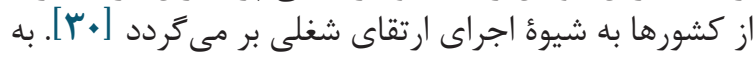

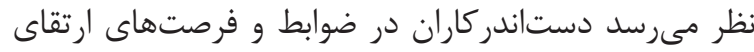

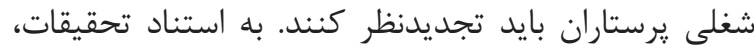




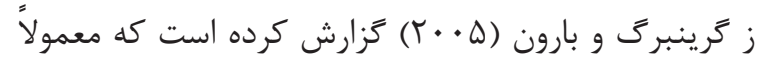

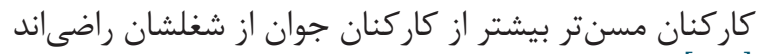

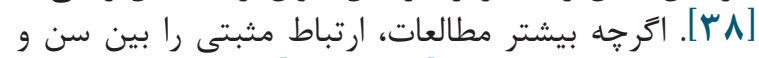

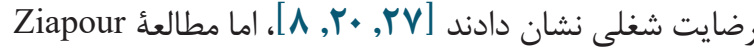

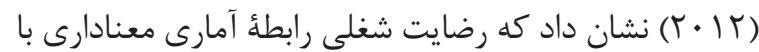

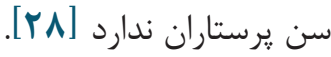

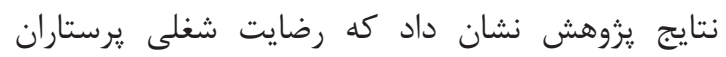

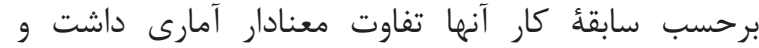
يرستاران در سالهاى اول اشتغالشان (سابقه كار زير دارئ

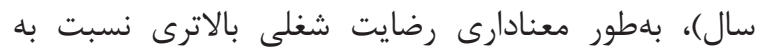

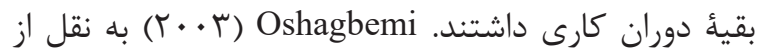

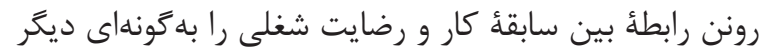

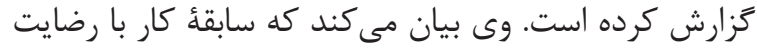

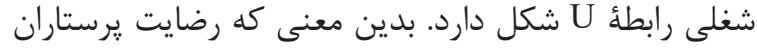

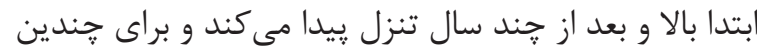

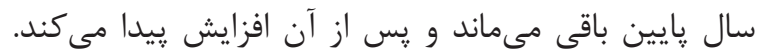

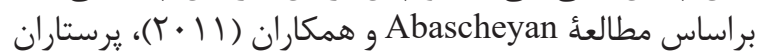

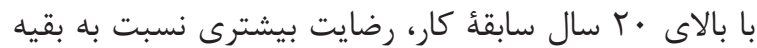

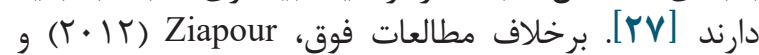
Luddy

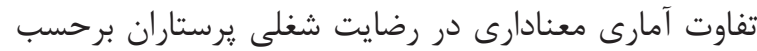

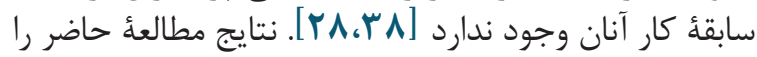

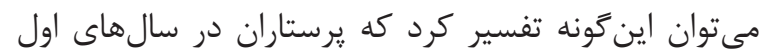

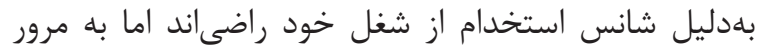

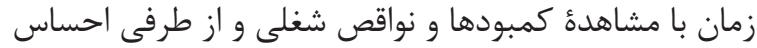

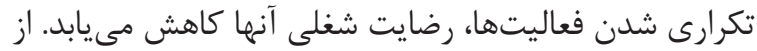

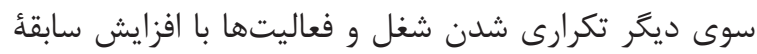

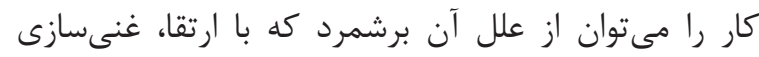

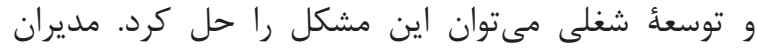

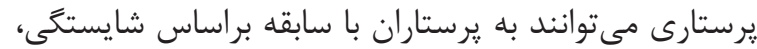

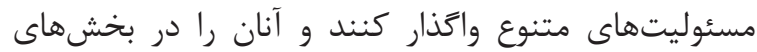
مختلف و غيرتكرارى به كار كيرند.

\section{نتيجهذَيرى}

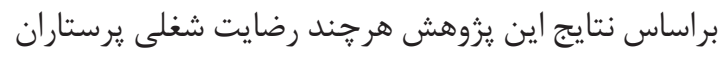

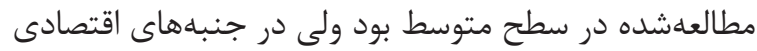

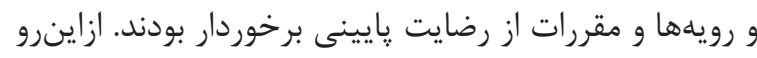

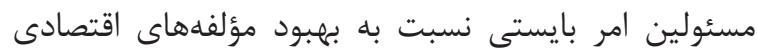

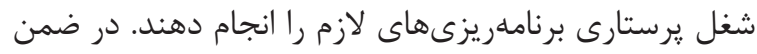

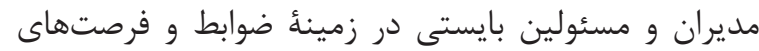

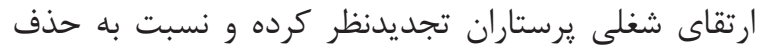

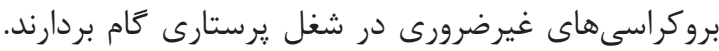

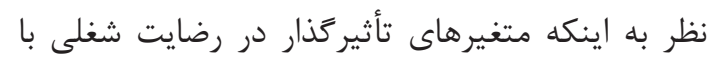

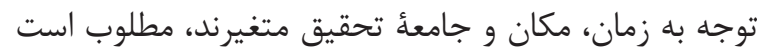

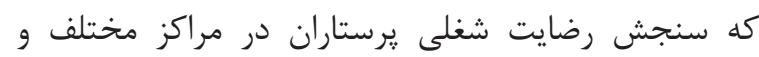

$$
\text { بلبصورت مكرر اندازمخيرى شود. }
$$

در قوانين مىتوانند از عوامل نارضايتى در اين حيطه باشند.

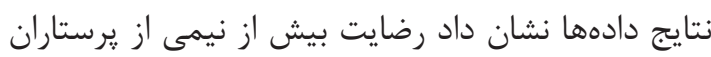

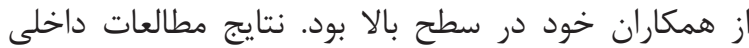

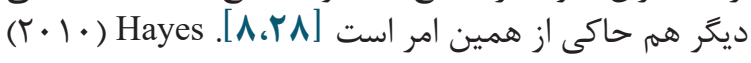

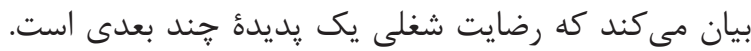

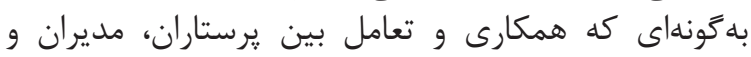

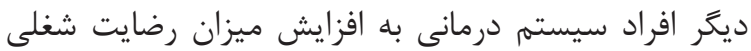

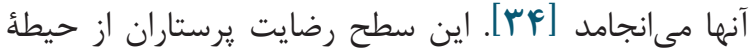

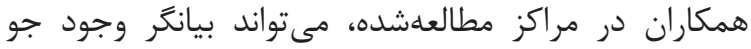
سازمانى و كار گروهى مطلوب دمان در اين مراكز باشد.

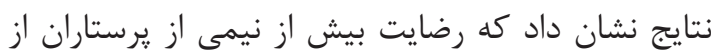

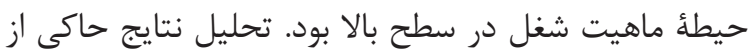

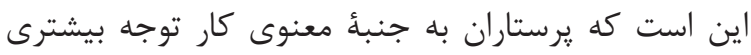

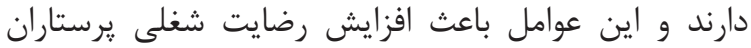

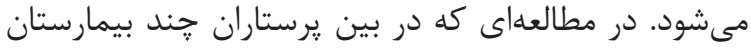

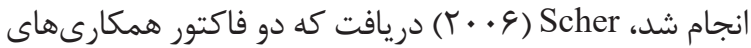
دوطرفه و طبيعت كار يرستارى عوامل مؤثر بر رضايت شغلى دارئ

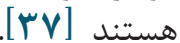

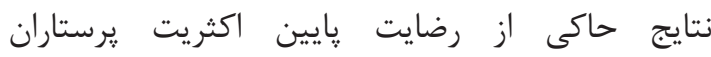

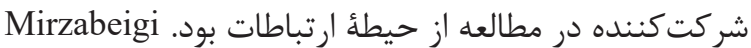

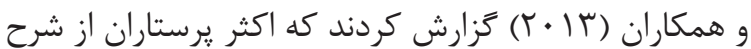

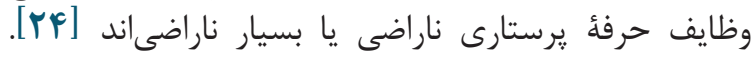

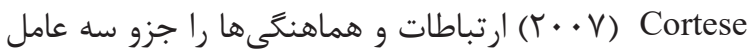

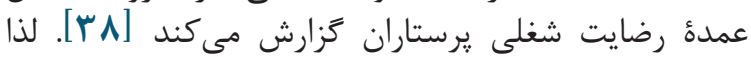

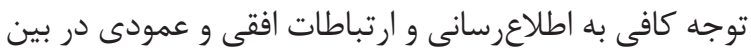

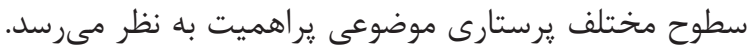

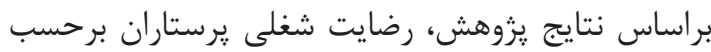

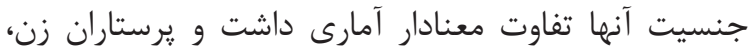

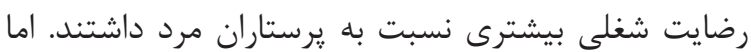

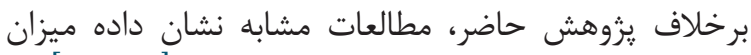

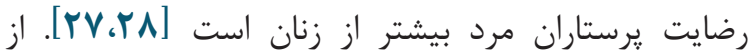

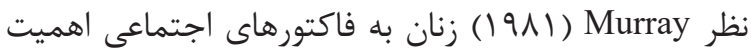

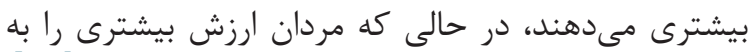

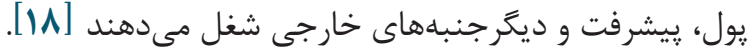

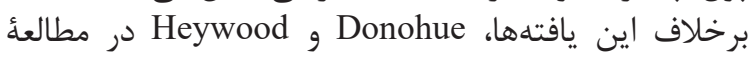
خود در بين يرسنل آمريكايى و انعليسى نتوانستند تفاوت إنات

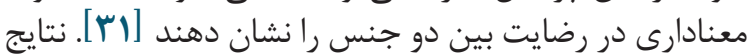

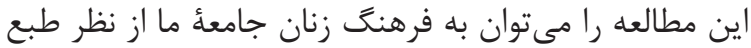

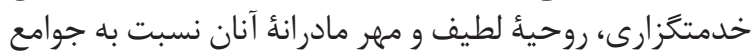

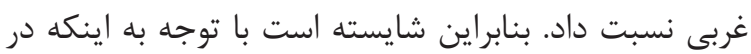

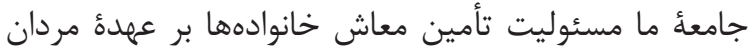

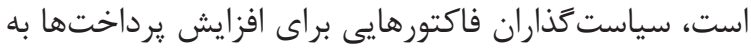

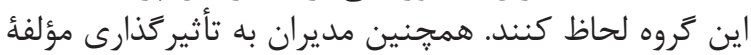

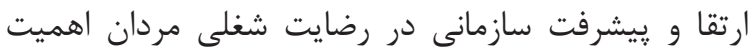
بيشترى دهند.

براساس نتايج يزوهش، رضايت شغلى ثرستاران برحسب

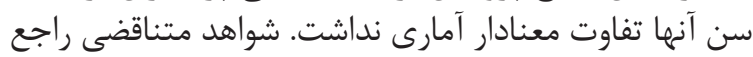

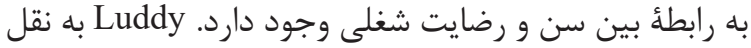


فاطمه קر اغى و همكاران.

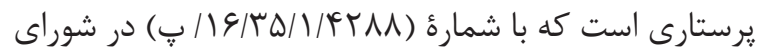

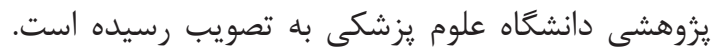

$$
\begin{aligned}
& \text { تضاد منافع } \\
& \text { در اين مطالعه تضاد منافع وجود ندارد. }
\end{aligned}
$$

$$
\begin{aligned}
& \text { سياسَزן ارى } \\
& \text { در يايان از كليئ مسئولين و پرستاران دانشعاه علوم }
\end{aligned}
$$

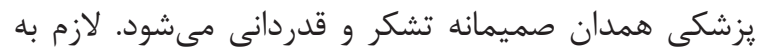

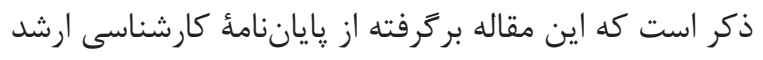

\section{References}

1. Hill J, Valdemar A. Employee Satisfaction and Organizational Commitment: A Mixed Methods Investigation of the Effects of Servant Leadership: ProQuest; 2008.

2. Locke EA. What is job satisfaction? Organizational behavior and human performance. 1969;4(4):309-36. https://doi.org/10.1016/0030$\underline{\text { 5073(69)90013-0 }}$

3. Brayfield AH, Rothe HF. Job satisfaction in nursing. J Appl Psychol. 2011;35(5):307. https://doi. org/10.1037/h0055617

4. Robbins SP, Judge TA. Organizational behavior. Translated by: Parsaeian, A Arabi, MA Trans. Tehran: Office of Cultural Research. 2001:16690 .

5. Larrabee JH, Janney MA, Ostrow CL, Withrow ML, Hobbs GR, Burant C. Predicting registered nurse job satisfaction and intent to leave. Journal of Nursing Administration. 2013;33(5):271-83. https://doi.org/10.1097/00005110-200305000$\underline{00003}$

6. Ingersoll GL, Olsan T, Drew-Cates J, DeVinney BC, Davies J. Nurses' job satisfaction, organizational commitment, and career intent. J Nurs Adm. 2012;32(5):250-63. https://doi. org/10.1097/00005110-200205000-00005

7. Roman L. Nursing shortage: looking to the future. RN. 2008;3(71):38-41.

8. Monjamed Z, Ghorbani T, Mostofian F, Oveissipour R, Mahmoudi M. A nationwide study of level of job satisfaction of nursing personnel in Iran. Hayat. 2004;10(4).

9. Herzberg F. The motivation to work. 6, editor: Transaction Publishers; 1993.

10. Fauziah N, Kamaruzaman J. Levels of job satisfaction amongst Malaysian academic staff. Asian Social Science. 2009;5:122-8.

11. Eyupoglu SZ, Saner T. Job satisfaction: Does rank make a difference? African Journal of Business Management. 2009;3(10):609-15.

12. Scheroder R. Job satisfaction of employees at a Christian university. Journal of Research on Christian Education. 2008;17:225-46. https://doi. org/10.1080/10656210802433467

13. Sadeghi A, Pihie L, Akmaliah Z, Elias H, Foo SF. Demographic analysis on academic staff's job satisfaction in Malaysian Research Universities. Pertanika Journal of Social Sciences \& Humanities. 2012;20(S):1-20.

14. Ghayasi A. Effect of Manager Leadership Style and Demographical Factors on Job Satisfaction of Nurses. Journal of Military Medicine. 2010;15(1):347-53.

15. Spector PE. Job satisfaction: Application, assessment, causes, and consequences: Sage; 1997. https://doi.org/10.4135/9781452231549

16. Akbaritabar A, Mokarami H, Nazifi M, Rahiminejad M, mirkamandar E, Hosseinpouri M. Psychometric properties of Spector's job satisfaction survey in the Iranian population. Koomesh. 2013;14(3):335-41.

17. Zaki M. Examination and reliabity of JSS. Knowledge reference. 2004;4(13):391-94.

18. Murray MA, Atkinson T. Gender differences in correlates of job satisfaction. Canadian Journal of Behavioural Science/Revue canadienne des sciences du comportement. 1981;13(1):44. https:// doi.org/10.1037/h0081119

19. Golparvar M, Javadian Z, Adibi Z. The relationship between job stress and job performance due to the mediating role of turnover and job satisfaction. Iran Occupational Health Journal. 2013; 10(1):33-42.

20. Shahbazi L, Salimi T. Job satisfaction in Yazd hospitals nurses. Journal of Shahid Sadoughi University of Medical Siences. 2002;10(3Suppl):70.

21. Tahriri, Batool, Honarvar, Hasan, Tavfighi, Shahram, et al. Realationship bitween job satisfaction and organational comittment in hospitals. Army Medecine. 2010;12:1-2.

22. Nolan M, Nolan J, Grant G. Maintaining nurses' job satisfaction and morale. Br J Nurs. 1995;4(19):1149-54. https://doi.org/10.12968/ bjon.1995.4.19.1149 PMid: $\underline{8535126}$

23. Movahed M, Haghighi Moghdam Y. An investigation of the job satisfaction and related factors in nurses of uromia University of Medical Sciences and Health Services. J Urmia Nurs Midwifery Fac. 2001;2(13):86-91.

24. Mirzabeigi G, Salemi S, Sanjari M, Shirazi F, Heidari S, Maleki S. Job Satisfaction among Iranian Nurses. Hayat. 2009;15(1):49-59. 
25. Papp I, Markkanen M, Bonsdorff M. Clinical environment as a learning environment: student nurses' perceptions concerning clinical learning experiences. Nurse Educ Today. 2003;23(4):262-8. https://doi.org/10.1016/S0260-6917(02)00185-5

26. Lu H, Barriball KL, Zhang X, While AE. Job satisfaction among hospital nurses revisited: a systematic review. Int J Nurs Stud. 2012;49(8):101738. https://doi.org/10.1016/j.ijnurstu.2011.11.009 PMid:22189097

27. Abascheyan R, Avazeh A, Rabee S. Job Satisfaction and its Related Factors among Nurses in the Public Hospitals of Zanjan University of Medical Sciences, 2010 Nurs Midwifery Care J. 2011;1(1):17-25

28. Ziapour A. An investigation of the job satisfaction and related factors in nurses of Kermanshah hospitals. J Nurs Manag. 2012;2(2):27-34.

29. Bjørk IT, Samdal GB, Hansen BS, Tørstad S, Hamilton GA. Job satisfaction in a Norwegian population of nurses: A questionnaire survey. Int J Nurs Stud. 2007;44(5):747-57. https://doi.org/10.1016/j.ijnurstu.2006.01.002 PMid: 16504197

30. Zangaro GA, Johantgen M. Registered nurses'job satisfaction in Navy hospitals. Military medicine. 2009;174(1): 76-81. https://doi.org/10.7205/ MILMED-D-04-1307

31. Donohue SM, Heywood JS. Job satisfaction and gender: an expanded specifica-

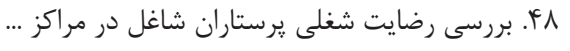

tion from the NLSY. International Journal of Manpower. 2004;25(2):211-38. https://doi. org/10.1108/01437720410536007

32. Cortese CG. Job satisfaction of Italian nurses: anexploratory study. J Nurs Manag. 2007;15(3):303-12. https://doi.org/10.1111/ j.1365-2834.2007.00694.x PMid: 17359430

33. Arch M, Greatz B. Work satisfaction unionism and militancy amongst nurses. Community Health Student. 1989;13(2):177-85. https://doi. org/10.1111/j.1753-6405.1989.tb00195.X

34. Hayes B, Bonner A, Pryor J. Factors contributing to nurse job satisfaction in the acute hospital setting: a review of recent literature. Journal of nursing management. 2010;18(7):804-14. https:// doi.org/10.1111/j.1365-2834.2010.01131.x PMid:20946216

35. Rezaeian A. Management of organizational behavior. Tehran: Tehran University School of Management Publications. 2008:286-7.

36. Kovner CT, Brewer CS, Greene W, Fairchild S. Understanding new registered nurses' intent to stay at their jobs. Nurs Econ. 2009;27(2):81-98. PMid:19492772

37. Scher KM. Conflict management style of nurse managers and its impact upon staff nurse job satisfaction: University of Bridgeport; 2006.

38. Luddy N. Job satisfaction amongst employees at a public health institution in the Western Cape: University of the Western Cape; 2005. 